\title{
Trends in Cardiovascular Risk Factors (1984-1993) in a Swiss Region: Results of Three Population Surveys ${ }^{1}$
}

\author{
Vincent Wietlisbach, B.A., ${ }^{, 2}$ Fred Paccaud, M.D., ${ }^{*}$ Martin Rickenbach, M.D., ${ }^{*}$ and \\ Felix Gutzwiller, M.D., Dr.Ph. $\dagger$ \\ *Institute of Social and Preventive Medicine, University of Lausanne, 1005 Lausanne, Switzerland; and $\dagger$ Institute of Social and \\ Preventive Medicine, University of Zurich, 8006 Zurich, Switzerland
}

Background. This study attempted to assess the time trends in lifestyle and cardiovascular risk factors in the Swiss region of Vaud-Fribourg (population 784,000).

Methods. Three surveys $(1984 / 1985,1988 / 1989$, and 1992/1993), based on independent representative samples $(n=3,300)$ of the population ages 25 to 74 , were conducted within the framework of the international WHO-MONICA Project.

Results. The most favorable changes were observed in reported behaviors: increased physical activity in leisure time, healthier dietary habits (switch from unskimmed milk, butter, and meat to skimmed milk, margarine, and fish, with no change for fruits and vegetables), and lower prevalence of regular smoking among men (from 32 to $28 \%$ ). Body mass index did not vary significantly, apart from an increase in the prevalence of obesity among men (from 11 to 15\%). Total cholesterol varied only slightly, while the HDL cholesterol levels decreased steadily (from 1.37 to 1.19 mmol/L among men; from 1.59 to 1.51 among women). Average systolic blood pressure regressed among women (from 127.2 to $124.4 \mathrm{~mm} \mathrm{Hg}$ ), while the prevalence of untreated hypertension increased among older men.

Conclusion. The self-reported changes in lifestyle were only partially reflected by favorable trends in objective measurements. Physical activity, even at moderate intensity, and consumption of fruits, vegetables, and fiber in general should be promoted.

๑) 1997 Academic Press

Key Words: health surveys; cardiovascular risk factors; coronary heart disease; Switzerland; HDL cholesterol; blood pressure; diet; physical activity.

\footnotetext{
${ }^{1}$ The MONICA-Switzerland study was funded by the Swiss National Science Foundation (Grants 3.856-0.83, 3.938.0.85, 329271.87, and 32-30110.90) and the canton of Vaud.

2 To whom reprint requests should be addressed at the Institut universitaire de médecine sociale et préventive, 17, rue du Bugnon, 1005 Lausanne, Switzerland. Fax: ++ 41213147373.
}

\section{INTRODUCTION}

Beneficial changes in known coronary heart disease (CHD) risk factors (such as diet, blood lipids, blood pressure, and smoking) have been found to be associated with the decline of mortality from CHD in many developed countries [1-4]. Aggregate data of food consumption and results of health surveys were used in general to monitor the evolution over time of the risk factor levels in the population. However in many countries, existing surveys were based on particular subgroups or were not periodically replicated, and extrapolating trends proved difficult under these circumstances [5]. Furthermore, to what extent the observed drop in CHD mortality resulted from reduction in risk had to be assessed against the potential concurrent influence of improved medical care. Such assessments have been attempted by reviewing and balancing the evidence from heterogeneous data sources $[6,7]$.

In Switzerland, as in most western European countries, the decline of mortality from CHD started in the 1970s with a delay of 10 to 15 years in comparison with the United States [8]. Time trends in dietary habits and CHD risk factor levels cannot be measured reliably before 1985 because no periodic population-based health survey had been conducted in the country up to that year. The present paper reports on the first assessment on such time trends based on three consecutive health examination surveys conducted in the Swiss region of Vaud-Fribourg over the period 19841993, within the framework of the international research project MONICA ("Monitoring of trends and determinants in cardiovascular disease"). The contribution of the observed risk factor changes to the CHD mortality fall can be sized up because time trends in hospitalization for acute ischemic heart disease, medical care, and case fatality were measured in parallel. These data are crucial in defining new strategies in the prevention of myocardial infarction at regional and national levels. 


\section{POPULATION AND METHODS}

\section{The MONICA Project}

The international research project was launched in 1980 by the World Health Organization to contribute to the understanding of changes in mortality from CHD [9]. The project consists in measuring with standardized instruments the trends in CHD risk factors, incidence, hospital management, case fatality, and mortality in various populations over a 10 -year period [10]. Thirty-eight regions in 21 countries participated in this study. Three Swiss cantons (Vaud, Fribourg, and Ticino) took part in the MONICA project. Data from the neighboring cantons of Vaud and Fribourg, situated in the southwestern part of Switzerland, predominantly French-speaking, with 784,000 inhabitants in 1990, are presented here.

\section{Sampling Procedure}

Trends in the prevalence of risk factors have been measured through three consecutive surveys (1984/ $1985,1988 / 1989$, and 1992/1993), based on independent representative samples of the resident population aged 25 to 74 years. The same two-stage sampling procedure was used in the three surveys [11]. First, a sample of 51 of the 651 communes of the region was drawn, after stratification according to their number of residents. Second, a random sample of the residents was drawn from the population files of the communes.

The selected persons were invited to attend a health examination in their commune of residence and to complete a self-administered questionnaire about their sociodemographic characteristics, dietary intakes, and lifestyle habits.

\section{Food Questionnaire}

The 24-h recall method was used, participants having to tick on a list of food items what they ate or drank on the day before the health examination. Other questions concerned specific dietary habits, and several scores were built empirically using these questions to characterize the responder's lifestyle. Consistent changes over time were observed in the score of "fatty diet," ranging from 0 to 4 and formed by adding 1 point for each of the following habits: buttering bread, cooking in butter, seldom cutting off apparent fat from meat, and drinking unskimmed milk. This score is probably the best indicator of fat intake that can be derived from the short food questionnaire.

\section{Physical Activity Questionnaire}

Participants were asked to categorize their physical activity at work, including household chores for housewives, into one of four proposed groups (mostly sitting, mostly standing or walking; moderate efforts, or heavy work) and their leisure-time activity into one of three groups (mostly sitting; regular walking, cycling, or gardening; or regular sports training). An additional question concerned the frequency of sports practice (never, rarely, once a week, or several times a week). The questionnaire has been validated with a more objective measure of physical activity, the number of impulses recorded by a pedometer worn during a week, in a subsample of participants of the second survey [12]. In both sexes, the average pedometer count was found to increase linearly across subjects classified into three categories: sedentary leisure, more active leisure, and participating in sports more than once a week. Therefore, a score of leisure-time physical activity was built up, worth 0,1 , and 2 according to whether the participant belonged to the first, second, or third category, respectively.

\section{Blood Lipids}

The subjects were nonfasting, the hour of the health examination varying from 8:00 to 20:00. A venous blood sample was drawn from each subject, with the tourniquet being loosened as soon as the blood flow was established. In the first survey blood was collected in heparin-containing tubes and the lipid concentrations were measured in plasma. In the second and third surveys, the blood samples were allowed to clot at room temperature and serum was used. In the three surveys, centrifugation took place within $2 \mathrm{hr}$.

Total cholesterol was determined enzymatically usually on the following day using a Boeringher testkit. The same method was applied to high-density lipoprotein (HDL) cholesterol after precipitation with magnesium phosphotungstate. No correction factor was used to allow for plasma-serum differences in total cholesterol concentrations as these differences are found not significantly different from 0 when using a heparinized anticoagulant in a recent study [13].

The laboratory determinations of total and HDL cholesterol satisfied the internal routine controls of intraday and interday repeatability. The WHO regional Lipid Reference Center for Europe, in Prague, organized continuous external quality control by sending blind sets of lyophilized samples periodically to the laboratories of all MONICA collaborating centers. Laboratory results were considered acceptable if their percentage of deviation from control sample value was not to exceed 5\% for total cholesterol and 7.5\% for HDL. In the Vaud-Fribourg region, laboratory performance satisfied the quality requirement for total cholesterol over the three surveys. Determination of HDL proved more problematic: a systematic bias was observed during the first survey period (1984-1985), with an underestimation of $15-20 \%$ of the HDL control sample values. Therefore HDL values of the first survey was multiplied by 1.17 to be corrected for this per- 
sistent deviation, attributed to a matrix effect in the use of the lyophilized samples [14].

The cutoff point for high cholesterol was fixed to 6.5 $\mathrm{mmol} / \mathrm{L}$ according to the recommendations of the Swiss Society of Cardiology [15].

\section{Body Mass Index}

Height and body weight were measured with participants standing without shoes and heavy outer garments. Body mass index (BMI) was calculated as weight divided by height squared $\left(\mathrm{kg} / \mathrm{m}^{2}\right)$ as a measure of relative weight. A BMI value over 30 served as definition of obesity for both sexes.

\section{Blood Pressure}

Blood pressure (BP) was measured two consecutive times on the right arm using a random-zero sphygmomanometer, with the subject in the sitting position after at least $15 \mathrm{~min}$ of rest. The observed values were recorded to the nearest $2 \mathrm{~mm} \mathrm{Hg}$ with diastolic blood pressure being determined at the beginning of Korotkoff phase V. Blood pressure levels were taken as the mean value of the two readings and WHO criteria were adopted in the definition of high blood pressure (systolic $\mathrm{BP} \geqslant 160 \mathrm{~mm} \mathrm{Hg}$ and/or diastolic $\mathrm{BP} \geqslant 95 \mathrm{~mm}$ $\mathrm{Hg}$ ). Participants were asked whether they had ever been told by medical personnel that their blood pressure was high and whether they had taken drugs for high blood pressure within 2 weeks prior to the examination. All the BP measurers followed the same training procedures in order to reduce to minimum the interindividual differences.

\section{Data Analysis}

The mean levels of the risk factors and the prevalence rates of persons at high risk are presented separately for each sex according to three age groups of roughly comparable size $(25-39,40-54$, and 55-74 years) and overall. Overall values are standardized by age, taking the Swiss population of the 1990 census as the reference population.

The between-surveys differences in the risk factor mean levels were tested for time trend using a linear model within the classical analysis of variance framework. Similarly the Mantel-Hanszel $\chi^{2}$ test for linear association was applied to assess the changes in the risk factor prevalence rates over the three surveys. All data analyses were carried out using the statistical software SPSS [16].

As participation rates varied substantially from survey to survey, inducing significant differences in the sociodemographic distribution of the participants (Table 1), the time trend analysis was run a second time by adjusting the risk factor levels for nationality and educational attainment. This adjustment corrected only slightly the risk factor levels and affected neither the magnitude of change nor the statistical significance of the time trends. Unadjusted results are therefore presented.

Further analytical efforts were aimed at identifying changes in lifestyle that are likely to have induced the observed changes in risk factors. To this purpose, the time trends in the responses to the lifestyle questionnaire were assessed in the same way as for risk factors within each sex-age group. If, in several of these groups, both the prevalence of a given lifestyle habit and the level of a given risk factor changed significantly over the study period (test for time trend with $P$ $<0.05$ ) and if their changes across the surveys were highly correlated (correlation coefficient $>90 \%$ ), the lifestyle habit was considered a potential determinant of the risk factor time trend.

\section{RESULTS}

\section{Participation}

Independent random samples of 3,300 persons were drawn for each of the three surveys, with successive overall participation rates of 57,61 , and $53 \%$. In the

TABLE 1

Sample Size, Participation Rates, and Characteristics of Participants According to Sex: MONICA-Switzerland, Vaud-Fribourg, 1984-1993

\begin{tabular}{|c|c|c|c|c|c|c|}
\hline & \multicolumn{3}{|c|}{ Men } & \multicolumn{3}{|c|}{ Women } \\
\hline & 1984-1985 & 1988-1989 & 1992-1993 & 1984-1985 & 1988-1989 & $1992-1993$ \\
\hline Sample size & 1,629 & 1,657 & 1,596 & 1,670 & 1,642 & 1,703 \\
\hline Participation rates $(\%)$ & 59.4 & 62.4 & 52.8 & 55.3 & 59.5 & 52.8 \\
\hline No. of participants & 968 & 1034 & 843 & 923 & 977 & 899 \\
\hline Age group $25-39(\%)$ & 37.1 & 37.6 & 37.1 & 38.7 & 35.7 & 37.9 \\
\hline Age group 40-54 (\%) & 34.5 & 31.6 & 36.4 & 31.5 & 34.1 & 36.2 \\
\hline Age group 55-74 (\%) & 28.4 & 30.8 & 26.5 & 29.8 & 30.2 & 25.9 \\
\hline Foreign nationality $(\%)$ & 13.6 & 19.9 & 19.9 & 10.2 & 12.0 & 15.8 \\
\hline Low educational attainment ${ }^{a}(\%)$ & 20.6 & 23.1 & 18.1 & 41.4 & 39.1 & 30.4 \\
\hline
\end{tabular}

\footnotetext{
${ }^{a}$ Obligatory school only (up to 15 years).
} 
three surveys, the highest participation rate was observed in the persons ages 40 to 54 , because it was more difficult to reach younger people and to convince older people. Participation was generally lower among women than among men, with a marked difference in the age group 55 to 74 . The variation of participation rates throughout the three surveys is attributable to various mechanisms. In the first survey, a poorer enrollment of foreigners was observed; in the third survey, the rejection rates were substantially higher in each sex and age group. The proportion of participants with low educational attainment remained relatively stable over time for men, whereas it dropped substantially in the last survey for women (Table 1).

\section{Smoking, Physical Activity, and Dietary Habits}

Changes over time in the three lifestyle indicators are presented in Table 2. The proportion of regular cigarette smokers reached a peak at the second survey in the age group 25 to 39 for both sexes. In the higher age groups ( 40 to 54 and 55 to 74 ), the prevalence of smokers decreased for men and increased for women over the three surveys, although the time trend was statistically significant only for middle-aged men. On the other hand, the average daily number of cigarettes (per current smoker) did not change significantly in either sex-age group (data not shown).

An increase over time in the mean score of reported leisure-time physical activity was observed among both sexes. This upward trend was the most marked in the older participants (55-74), with a high level of statistical significance. On the other hand, the proportion of men reporting moderate or high physical activity at work declined significantly (from 33\% in 1984-1985 to $27 \%$ in $1992-1993)$.

A decline in the score of fatty diet was observed over the study period in each sex-age group. This trend is compatible with substantial changes over time in the responses to the 24-h recall food questionnaire, as represented in Fig. 1. There was an significant upward trend in the intake of margarine (from $32 \%$ in 19841985 to $38 \%$ in $1992-1993$ ), skimmed milk (from 18 to $23 \%$ ), and fish (from 10 to $16 \%$ ), with a corresponding decline in the daily intake of butter (from 75 to $65 \%$ ), unskimmed milk (from 40 to $31 \%$ ), and meat (from 85 to $80 \%$ ). Only minor changes were observed for fruits (from 68 to $69 \%$ ), raw vegetables (from 70 to $71 \%$ ), and starches (from 97 to $98 \%$ ). The intake of wine decreased significantly over time (from 47 to 39\%), especially among men, who tended to more frequent beer drinking.

\section{Blood Lipids}

The mean level of total cholesterol, as well as the prevalence of high cholesterol, rose from the first to the second survey and turned back in the third survey, whereas mean HDL cholesterol levels decreased steadily and significantly over time (Table 3). This pattern of evolution of the blood lipids was observed among both sexes across all age groups, except among older women, whose HDL mean level remained stable throughout the three surveys. The decline in average HDL cholesterol was more marked among men than among women.

Among significant time trends in lifestyle factors, the declining score of fatty diet emerges as a potential

TABLE 2

Trends in Smoking, Leisure-Time Physical Activity, and Dietary Habits According to Sex and Age: MONICA-Switzerland, Vaud-Fribourg, 1984-1993

\begin{tabular}{|c|c|c|c|c|c|c|c|c|c|c|c|}
\hline \multirow[b]{3}{*}{ Variable } & \multirow[b]{3}{*}{ Age } & \multicolumn{5}{|c|}{ Men } & \multicolumn{5}{|c|}{ Women } \\
\hline & & \multicolumn{3}{|c|}{ Survey } & \multicolumn{2}{|c|}{ Trend } & \multicolumn{3}{|c|}{ Survey } & \multicolumn{2}{|c|}{ Trend } \\
\hline & & $1984-1985$ & 1988-1989 & $\overline{1992-1993}$ & Change $^{a}$ & $P^{b}$ & 1984-1985 & 1988-1989 & $\overline{1992-1993}$ & Change $^{a}$ & $P^{b}$ \\
\hline \multirow{4}{*}{$\begin{array}{l}\text { Regular } \\
\text { cigarette } \\
\text { smokers }(\%)\end{array}$} & $25-74^{c}$ & 32.3 & 34.2 & 27.8 & -4.5 & $*$ & 22.8 & 25.5 & 24.8 & +2.0 & NS \\
\hline & $25-39$ & 36.2 & 42.7 & 37.1 & +0.9 & NS & 32.5 & 37.2 & 32.8 & +0.3 & NS \\
\hline & $40-54$ & 33.5 & 32.1 & 23.8 & -9.7 & $* *$ & 20.6 & 22.8 & 25.2 & +4.6 & NS \\
\hline & $55-74$ & 25.8 & 25.5 & 20.2 & -5.6 & NS & 12.7 & 13.2 & 13.7 & +1.0 & NS \\
\hline \multirow{4}{*}{$\begin{array}{l}\text { Score of } \\
\text { physical } \\
\text { activity } \\
\text { (mean) }\end{array}$} & $25-74^{c}$ & 0.87 & 0.93 & 1.01 & +0.14 & $* * *$ & 0.75 & 0.80 & 0.88 & +0.13 & $* * *$ \\
\hline & $25-39$ & 0.93 & 1.00 & 1.08 & +0.15 & $* *$ & 0.86 & 0.82 & 0.93 & +0.07 & NS \\
\hline & $40-54$ & 0.88 & 0.88 & 0.95 & +0.09 & NS & 0.76 & 0.82 & 0.87 & +0.11 & NS \\
\hline & $55-74$ & 0.79 & 0.89 & 1.00 & +0.21 & $* * *$ & 0.60 & 0.74 & 0.82 & +0.22 & $* * *$ \\
\hline \multirow{4}{*}{$\begin{array}{l}\text { Score of } \\
\text { fatty diet } \\
\text { (mean) }\end{array}$} & 25-74 ${ }^{c}$ & 2.00 & 1.91 & 1.80 & -0.20 & $* * *$ & 1.75 & 1.48 & 1.47 & -0.28 & $* * *$ \\
\hline & $25-39$ & 2.08 & 1.96 & 1.92 & -0.16 & NS & 1.86 & 1.60 & 1.56 & -0.30 & $* * *$ \\
\hline & $40-54$ & 1.94 & 1.84 & 1.75 & -0.19 & $*$ & 1.76 & 1.43 & 1.45 & -0.31 & $* * *$ \\
\hline & $55-74$ & 1.96 & 1.92 & 1.72 & -0.14 & $*$ & 1.60 & 1.37 & 1.36 & -0.24 & $*$ \\
\hline
\end{tabular}

\footnotetext{
${ }^{a}$ Change from 1984-1985 survey to 1992-1993 survey.

${ }^{b}$ Test for time trend over the three surveys (see Population and Methods): $* P<0.05 ; * * P<0.01 ; * * * P<0.005$; NS, not significant.

${ }^{c}$ Directly age standardized with the 1990-census Swiss population as standard.
} 


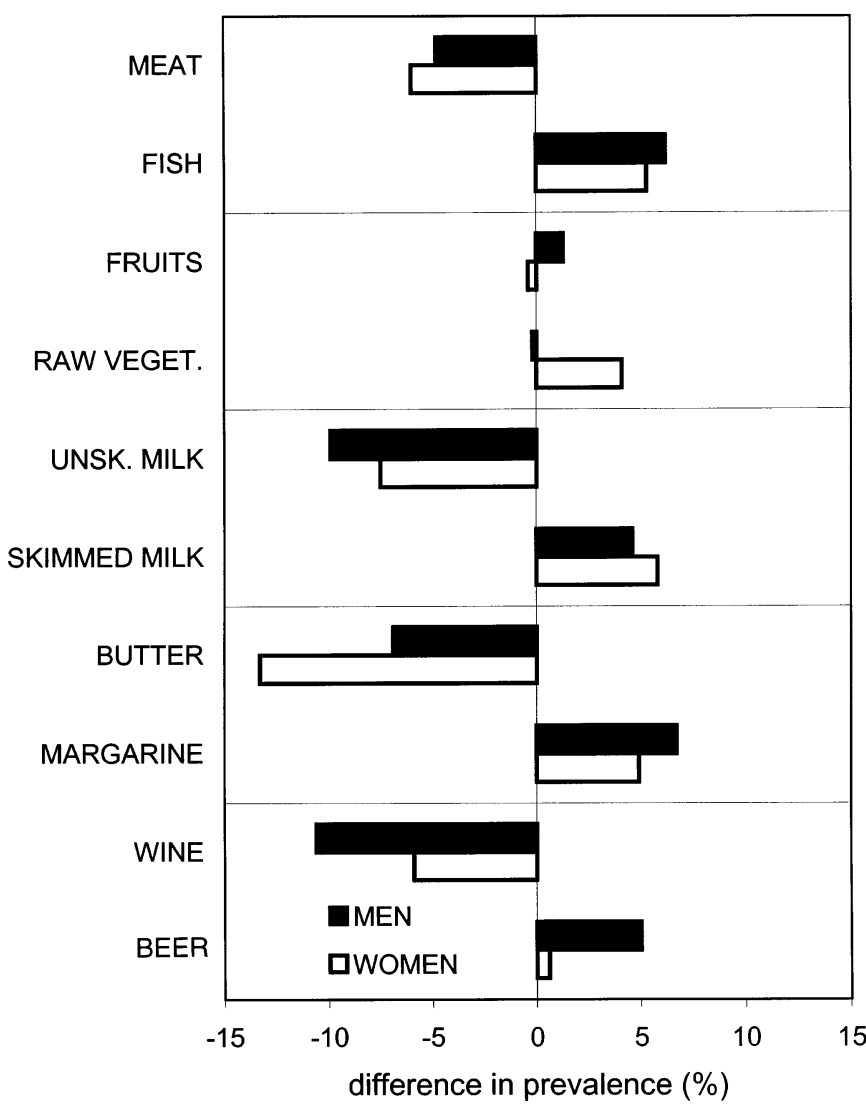

FIG. 1. Daily intakes of selected foods and drinks: difference in prevalence rates between first survey (1984-1985) and third survey (1992-1993).

determinant of the HDL cholesterol decline among both sexes, according to the criteria defined under Population and Methods. Furthermore, the falling frequency of wine drinking and the rising frequency of fish eating come out as other potential determinants among men.

\section{Body Mass Index}

Weight and height tended to increase in parallel over the three surveys in most age groups (data not shown). As a result little change was observed in mean BMI levels apart from a significant upward trend for women ages 55 to 74 (Table 4 ). The prevalence of obesity varied significantly over time only in middle-aged men for whom the declining rate of regular cigarette smokers appears as a potential determinant of their gain in BMI.

\section{Blood Pressure}

Both systolic and diastolic mean levels, as well as the prevalence of high blood pressure, increased significantly among men ages 55 to 74 . Similar tendencies were only sketched out in those ages 40 to 54 and absent among younger men. Women experienced a $3 \mathrm{~mm}$
$\mathrm{Hg}$ decline of their average systolic blood pressure in all age groups, whereas no time trend was observed in their diastolic values (Table 5). Changes over time in the distribution of blood pressure values also differed between sexes. The distributions of both male systolic and diastolic values stretched out to the right in the age group 55 to 74 while the whole distribution of female systolic blood pressure has shifted down by $3 \mathrm{~mm}$ $\mathrm{Hg}$ in all age groups. The rising prevalence of high blood pressure among older men was mainly due to an increase in the prevalence of untreated hypertension. The proportion of men ages 50 to 74 showing high blood pressure values at health examination and not currently undergoing drug treatment nearly doubled from $11 \%$ in the first survey to $20 \%$ in the third. In the three surveys, half of these men were already medically screened for high blood pressure.

For women in the age groups 25 to 39 and 40 to 54, the decreases in the mean score of fatty diet and in the frequency of meat intake fulfill the criteria for being considered potential determinants of the downward trend in their average systolic blood pressure.

\section{CHD Event Rate}

Changes over time in CHD mortality in the VaudFribourg region can be monitored using the data of the federal statistics of deaths. The annual agestandardized CHD mortality rate (ICD-8 410-414) in the population ages 25 to 74 decrease by $28 \%$ for men (from 149 in 1985-1987 to 108 in 1991-1993, per 100,000 persons) and by $19 \%$ for women (from 38 to $31)$. On the other hand, as part of the MONICA project, all the hospital admissions due to myocardial infarction (with probable or definite diagnosis) have been registered during the study period among men. In the latter, the hospitalization rate regressed by $10 \%$ (from 247 to 221). Finally, adding up these hospital admissions and CHD deaths (apart from deaths within 28 days of hospital admission in order to avoid double counts) allows the calculation of the overall male CHD event rate, which declined by $14 \%$ (from 366 to 313 ).

\section{International Comparison}

The CHD risk profile, incidence, and mortality rate of the Vaud-Fribourg region in 1984 can be outlined from comparative data of the 38 MONICA collaborating centers $[10,17]$. The Swiss region ranked low for CHD event rates and mortality rate and, with respect to risk factors, low for blood pressure levels, middle for BMI levels and the prevalence of cigarette smoking, and among the highest for total cholesterol levels. No data were presented for HDL cholesterol.

The risk factor changes over the period 1984-1993 can be compared with similar trends reported from consecutive health examination surveys in West Ger- 
TABLE 3

Trends in Blood Lipids According to Sex and Age: MONICA-Switzerland, Vaud-Fribourg, 1984-1993

\begin{tabular}{|c|c|c|c|c|c|c|c|c|c|c|c|}
\hline \multirow[b]{3}{*}{ Variable } & \multirow[b]{3}{*}{ Age } & \multicolumn{5}{|c|}{ Men } & \multicolumn{5}{|c|}{ Women } \\
\hline & & \multicolumn{3}{|c|}{ Survey } & \multicolumn{2}{|c|}{ Trend } & \multicolumn{3}{|c|}{ Survey } & \multicolumn{2}{|c|}{ Trend } \\
\hline & & 1984-1985 & 1988-1989 & $1992-1993$ & Change $^{a}$ & $P^{b}$ & 1984-1985 & 1988-1989 & $\overline{1992-1993}$ & Change $^{a}$ & $P^{b}$ \\
\hline \multirow{4}{*}{$\begin{array}{l}\text { Mean total } \\
\text { cholesterol } \\
(\mathrm{mmol} / \mathrm{L})\end{array}$} & $25-74^{c}$ & 6.22 & 6.36 & 6.13 & -0.09 & NS & 6.06 & 6.19 & 5.99 & -0.07 & NS \\
\hline & $25-39$ & 5.81 & 5.94 & 5.76 & -0.05 & NS & 5.42 & 5.60 & 5.42 & -0.01 & NS \\
\hline & $40-54$ & 6.53 & 6.71 & 6.35 & -0.18 & NS & 6.13 & 6.21 & 5.95 & -0.18 & NS \\
\hline & $55-74$ & 6.42 & 6.49 & 6.38 & -0.04 & NS & 6.81 & 6.93 & 6.80 & -0.01 & NS \\
\hline \multirow{4}{*}{$\begin{array}{l}\text { Prevalence }(\%) \\
\text { of high total } \\
\text { cholesterol } \\
(>6.5 \mathrm{mmol} / \mathrm{L})\end{array}$} & $25-74^{c}$ & 35.9 & 38.8 & 33.2 & -2.7 & NS & 30.2 & 33.4 & 29.3 & -0.9 & NS \\
\hline & 25-39 & 24.0 & 27.5 & 22.0 & -2.0 & NS & 12.9 & 15.2 & 11.4 & -1.4 & NS \\
\hline & $40-54$ & 44.9 & 49.8 & 38.1 & -6.8 & NS & 31.6 & 34.5 & 27.1 & -4.5 & NS \\
\hline & $55-74$ & 41.5 & 40.9 & 42.2 & +0.7 & $\mathrm{NS}$ & 51.3 & 55.9 & 55.4 & +4.1 & NS \\
\hline \multirow{4}{*}{$\begin{array}{l}\text { Mean HDL } \\
\text { cholesterol } \\
(\mathrm{mmol} / \mathrm{L})\end{array}$} & $25-74^{c}$ & 1.37 & 1.26 & 1.19 & -0.18 & $* * *$ & 1.59 & 1.55 & 1.51 & -0.08 & $* * *$ \\
\hline & $25-39$ & 1.37 & 1.25 & 1.18 & -0.19 & $* * *$ & 1.60 & 1.56 & 1.52 & -0.08 & $* * *$ \\
\hline & $40-54$ & 1.38 & 1.27 & 1.20 & -0.18 & $* * *$ & 1.65 & 1.55 & 1.54 & -0.11 & $* * *$ \\
\hline & $55-74$ & 1.34 & 1.26 & 1.21 & -0.13 & $* * *$ & 1.51 & 1.55 & 1.47 & -0.04 & NS \\
\hline
\end{tabular}

${ }^{a}$ Change from 1984-1985 survey to 1992-1993 survey.

${ }^{b}$ Test for time trend over the three surveys (see Population and Methods): $* * * P<0.005$; NS, not significant.

${ }^{c}$ Directly age standardized with the 1990-census Swiss population as standard.

many [18], Finland [19], and the United States [20,21]. The results of these studies are summarized in Table 6.

The changes over time in the proportion of regular smokers are strikingly similar in the different countries, both for the direction and for the magnitude of change according to sex, irrespective of the current prevalence of smoking. Average concentrations of total cholesterol are similar in the Vaud-Fribourg region and in Germany, and much higher than in the other countries. Swiss levels have begun to decline over the past years while German levels are still rising. The United States and Finland experienced a steady decrease in total cholesterol since 1970 which persisted over the study period. The HDL cholesterol concentrations measured in the Vaud-Fribourg region are on average lower than the German levels and comparable to the American levels. However, mean HDL cholesterol values decreased over the past decade in the Swiss region while they increased in Germany and the United States. In parallel, higher levels and a more marked increase over time were observed for BMI in the two latter countries. Blood pressure offers the most contrasted evolution, with a substantial decrease in both systolic and diastolic values for both sexes in Finland (where the initial levels were, however, very high), but with more complex pattern of change in Germany and Switzerland.

\section{DISCUSSION}

Risk factors were monitored in the Vaud-Fribourg region, as in all MONICA centers, through periodic

TABLE 4

Trends in Body Mass Index According to Sex and Age: MONICA-Switzerland, Vaud-Fribourg, 1984-1993

\begin{tabular}{|c|c|c|c|c|c|c|c|c|c|c|c|}
\hline \multirow[b]{3}{*}{ Variable } & \multirow[b]{3}{*}{ Age } & \multicolumn{5}{|c|}{ Men } & \multicolumn{5}{|c|}{ Women } \\
\hline & & \multicolumn{3}{|c|}{ Survey } & \multicolumn{2}{|c|}{ Trend } & \multicolumn{3}{|c|}{ Survey } & \multicolumn{2}{|c|}{ Trend } \\
\hline & & $1984-1985$ & 1988-1989 & $1992-1993$ & Change $^{a}$ & $\overline{P^{b}}$ & 1984-1985 & 1988-1989 & $1992-1993$ & Change $^{a}$ & $P^{b}$ \\
\hline \multirow{4}{*}{$\begin{array}{c}\text { Mean BMI } \\
\left(\mathrm{kg} / \mathrm{m}^{2}\right)\end{array}$} & $25-74^{c}$ & 25.9 & 25.8 & 26.1 & +0.2 & NS & 24.4 & 24.7 & 24.6 & +0.2 & NS \\
\hline & $25-39$ & 24.9 & 24.7 & 24.8 & -0.1 & NS & 23.1 & 23.0 & 22.9 & -0.2 & $\mathrm{NS}$ \\
\hline & $40-54$ & 26.2 & 26.2 & 26.7 & +0.5 & NS & 24.9 & 24.7 & 24.6 & -0.3 & NS \\
\hline & $55-74$ & 27.0 & 26.7 & 27.3 & +0.3 & NS & 25.7 & 26.8 & 26.7 & +1.0 & * \\
\hline \multirow{4}{*}{$\begin{array}{l}\text { Prevalence (\%) } \\
\text { of obesity } \\
\quad\left(\text { BMI }>30 \mathrm{~kg} / \mathrm{m}^{2}\right)\end{array}$} & $25-74^{c}$ & 11.4 & 10.7 & 14.6 & +3.2 & $*$ & 10.8 & 10.6 & 10.1 & -0.7 & NS \\
\hline & $25-39$ & 6.1 & 4.6 & 7.0 & +0.9 & NS & 3.4 & 4.0 & 5.3 & +1.7 & NS \\
\hline & $40-54$ & 10.8 & 12.2 & 17.9 & +7.1 & $* *$ & 13.1 & 9.0 & 8.3 & -4.8 & NS \\
\hline & $55-74$ & 18.9 & 17.0 & 20.6 & +1.7 & NS & 17.8 & 21.0 & 18.5 & +0.7 & NS \\
\hline
\end{tabular}

${ }^{a}$ Change from 1984-1985 survey to 1992-1993 survey.

${ }^{b}$ Test for time trend over the three surveys (see Population and Methods): $* P<0.05$; $* * P<0.01$; NS, not significant.

${ }^{c}$ Directly age standardized with the 1990-census Swiss population as standard. 
TABLE 5

Trends in Blood Pressure According to Sex and Age: MONICA-Switzerland, Vaud-Fribourg, 1984-1993

\begin{tabular}{|c|c|c|c|c|c|c|c|c|c|c|c|}
\hline \multirow[b]{3}{*}{ Variable } & \multirow[b]{3}{*}{ Age } & \multicolumn{5}{|c|}{ Men } & \multicolumn{5}{|c|}{ Women } \\
\hline & & \multicolumn{3}{|c|}{ Survey } & \multicolumn{2}{|c|}{ Trend } & \multicolumn{3}{|c|}{ Survey } & \multicolumn{2}{|c|}{ Trend } \\
\hline & & 1984-1985 & 1988-1989 & $1992-1993$ & Change $^{a}$ & $P^{b}$ & 1984-1985 & 1988-1989 & $1992-1993$ & Change $^{a}$ & $P^{b}$ \\
\hline \multirow{4}{*}{$\begin{array}{l}\text { Mean systolic BP } \\
\quad(\mathrm{mm} \mathrm{Hg})\end{array}$} & $25-74^{c}$ & 132.4 & 131.1 & 133.4 & +1.0 & NS & 127.2 & 125.4 & 124.4 & -2.8 & $* * *$ \\
\hline & $25-39$ & 127.2 & 124.9 & 126.9 & -0.3 & NS & 117.1 & 116.2 & 114.6 & -2.5 & $* *$ \\
\hline & $40-54$ & 131.7 & 129.5 & 131.5 & -0.2 & $\mathrm{NS}$ & 126.0 & 124.3 & 122.8 & -3.2 & $*$ \\
\hline & $55-74$ & 139.9 & 141.1 & 143.9 & +4.0 & $*$ & 141.8 & 138.9 & 138.9 & -2.9 & NS \\
\hline \multirow{4}{*}{$\begin{array}{l}\text { Mean diastolic BP } \\
\quad(\mathrm{mm} \mathrm{Hg})\end{array}$} & $25-74^{c}$ & 81.5 & 79.2 & 83.1 & +1.6 & $* *$ & 76.8 & 74.7 & 77.1 & +0.3 & NS \\
\hline & $25-39$ & 79.3 & 76.7 & 79.4 & +0.1 & $\mathrm{NS}$ & 73.0 & 71.2 & 73.0 & 0.0 & $\mathrm{NS}$ \\
\hline & $40-54$ & 83.5 & 80.6 & 85.3 & +1.7 & $*$ & 78.5 & 75.6 & 78.6 & +0.1 & NS \\
\hline & $55-74$ & 82.2 & 80.9 & 85.5 & +3.3 & $* * *$ & 80.0 & 78.3 & 80.8 & +0.8 & NS \\
\hline Prevalence $(\%)$ & $25-74^{c}$ & 12.2 & 9.6 & 16.8 & +4.6 & $* *$ & 9.8 & 6.3 & 8.4 & -1.0 & NS \\
\hline of high BP & $25-39$ & 6.7 & 2.3 & 6.1 & -0.5 & $\mathrm{NS}$ & 2.5 & 0.6 & 1.5 & -1.0 & NS \\
\hline (systolic $\geqslant 160$ and/or & $40-54$ & 14.4 & 10.1 & 18.6 & +4.2 & $\mathrm{NS}$ & 7.9 & 3.6 & 6.8 & -1.1 & NS \\
\hline diastolic $\geqq 95)$ & $55-74$ & 17.1 & 18.6 & 28.7 & +11.6 & $* * *$ & 21.5 & 16.9 & 19.3 & -2.2 & NS \\
\hline
\end{tabular}

${ }^{a}$ Change from 1984-1985 survey to 1992-1993 survey.

${ }^{b}$ Test for time trend over the three surveys (see Population and Methods): $* P<0.05 ; * * P<0.01$; $* * * P<0.005$; NS, not significant.

${ }^{c}$ Directly age standardized with the 1990-census Swiss population as standard.

population-based health examination surveys using standardized sampling and measurement methods. However, maintaining comparable observational conditions over a 10 -year period is a difficult process because of unavoidable changes in population selection, enrollment, examiners, and laboratory. Therefore certain observed risk factor time trends might be due to drifts in the sampling, participation, or measurement biases. Adjustment methods and correction factors used to control for these biases are described and justified under Population and Methods.

The overall participation rates in the Vaud-Fribourg region, which varied between 53 and $61 \%$ in the three surveys, were low in comparison with those observed in the other MONICA centers, ranging from 54 to $89 \%$ [17]. However the level of participation has to be appraised in relation to the sampling frame, which was actually population based, including foreigners and in-

TABLE 6

Recently Reported Trends in Major Cardiovascular Risk Factors in Different Countries: Mean Annual Change and Current Risk Factor Levels

\begin{tabular}{|c|c|c|c|c|c|c|c|c|c|}
\hline & & \multicolumn{2}{|c|}{ Switzerland } & \multicolumn{2}{|c|}{ Germany } & \multicolumn{2}{|c|}{ Finland } & \multicolumn{2}{|c|}{ United States } \\
\hline Region & & \multicolumn{2}{|c|}{ Vaud-Fribourg } & \multicolumn{2}{|c|}{ Whole country } & \multicolumn{2}{|c|}{ North Karelia } & \multicolumn{2}{|c|}{ Whole country } \\
\hline Age group & & \multicolumn{2}{|c|}{$25-74$} & \multicolumn{2}{|c|}{$25-69$} & \multicolumn{2}{|c|}{$30-59$} & \multicolumn{2}{|c|}{$20-74$} \\
\hline Study period & & \multicolumn{2}{|c|}{ 1984-1993 } & \multicolumn{2}{|c|}{ 1984-1991 } & \multicolumn{2}{|c|}{ 1982-1992 } & \multicolumn{2}{|c|}{ 1976-1991 } \\
\hline \multicolumn{2}{|l|}{ No. of surveys } & \multicolumn{2}{|c|}{3} & \multicolumn{2}{|c|}{3} & \multicolumn{2}{|c|}{3} & \multicolumn{2}{|c|}{2} \\
\hline & & Men & Women & Men & Women & Men & Women & Men & Women \\
\hline \multirow[t]{2}{*}{ Regular smoker (\%) } & Change $^{a}$ & -0.56 & +0.28 & -0.40 & +0.22 & -0.40 & +0.20 & NA & NA \\
\hline & Final level & 27.8 & 25.1 & 39.2 & 28.0 & 32.0 & 17.0 & & \\
\hline \multirow{2}{*}{$\begin{array}{l}\text { Cholesterol } \\
(\text { mean in } \mathrm{mmol} / \mathrm{L})\end{array}$} & Change $^{a}$ & -0.011 & -0.011 & +0.015 & +0.013 & -0.045 & -0.055 & -0.013 & -0.019 \\
\hline & Final level & 6.14 & 5.97 & 6.09 & 6.16 & 5.85 & 5.56 & 5.30 & 5.30 \\
\hline \multirow{2}{*}{$\begin{array}{l}\text { Prevalence chol } \\
\quad>6.5(\%)\end{array}$} & Change $^{a}$ & -0.40 & -0.34 & NA & NA & -1.20 & -2.20 & -0.50 & -0.66 \\
\hline & Final level & 33.2 & 28.5 & & & 28.0 & 17.0 & 13.0 & 15.0 \\
\hline \multirow{2}{*}{$\begin{array}{l}\text { HDL cholesterol } \\
\quad(\text { mean in } \mathrm{mmol} / \mathrm{L})\end{array}$} & Change $^{a}$ & -0.023 & -0.010 & +0.005 & +0.012 & NA & NA & +0.003 & +0.004 \\
\hline & Final level & 1.19 & 1.51 & 1.34 & 1.74 & & & 1.19 & 1.45 \\
\hline \multirow{2}{*}{$\begin{array}{l}\text { BMI } \\
\quad\left(\text { mean in } \mathrm{kg} / \mathrm{m}^{2}\right)\end{array}$} & Change $^{a}$ & +0.03 & +0.01 & +0.05 & +0.07 & NA & NA & +0.07 & +0.07 \\
\hline & Final level & 26.1 & 24.5 & 26.8 & 26.2 & & & 26.3 & 26.3 \\
\hline \multirow{2}{*}{$\begin{array}{l}\text { Systolic blood pressure } \\
(\text { mean in } \mathrm{mm} \mathrm{Hg})\end{array}$} & Change $^{a}$ & +0.09 & -0.43 & +0.10 & +0.38 & -0.32 & -0.56 & NA & NA \\
\hline & Final level & 133.1 & 123.9 & 135.3 & 131.1 & 141.5 & 135.5 & & \\
\hline \multirow{2}{*}{$\begin{array}{l}\text { Diastolic blood pressure } \\
(\text { mean in } \mathrm{mm} \mathrm{Hg})\end{array}$} & Change $^{a}$ & +0.09 & +0.03 & -0.10 & +0.08 & -0.21 & -0.50 & NA & NA \\
\hline & Final level & 83.1 & 77.0 & 83.4 & 80.3 & 84.6 & 79.5 & & \\
\hline
\end{tabular}

\footnotetext{
${ }^{a}$ Change from first to last survey, divided by the number of in-between years.
} 
stitutionalized persons. Poor enrollment raises the possibility of underrepresentativeness of groups of population at particular risk for CHD and may lead to systematic biases in the assessment of the associated risk factors levels in either survey. To identify such potential biases, the participants of the second survey in the Vaud-Fribourg region were compared with the nonparticipants who agreed to answer a short health questionnaire [22]. Sedentary leisure-time activity and a previous cholesterol screening were found significantly more prevalent among nonparticipants. These characteristics were associated with higher total cholesterol levels in each survey, but the intersurvey changes in their prevalence rates do not correlate with the changes in blood lipids.

The MONICA surveys were designed to monitor a large spectrum of CHD risk factor levels in representative samples of the overall population, and this perspective limits the use of sophisticated instruments like high-technology investigation procedures or elaborate questionnaires. On one hand, it is a difficult task to select relevant measures and indicators from a list of CHD risk factors [23] which has to be updated periodically. For example, in this study, fibrinogen and postprandial lipids were not measured. On the other hand, a quantitative nutrition questionnaire would have provided a more reliable assessment of the habitual diet than the questionnaire based on the 24 -h recall method [24]. Furthermore, it would have brought information about intake of calories, fat, fiber, sodium, potassium, alcohol, coffee, and micronutrients. However the reported changes over time in diet were overall coherent.

The changes in smoking habits across the three surveys, in the Vaud-Fribourg region, differed according to the age group. The proportion of regular cigarette smokers turned back consistently for both sexes in the age group 25 to 39 years and this reversion, while needing statistical confirmation, has to be encouraged practically. In the higher age groups, the prevalence of smoking dropped for men and rose for women. Specific measures should be taken to weaken the increasing female proneness to cigarettes, especially among middle-aged women who also became significantly more reluctant to stop smoking (data not shown). The number of cigarettes smoked per day changed little on average, but an upward trend may have been obscured by an increase in underreporting over time, as observed in other countries $[19,25]$. However social and political acceptability of smoking is high in Switzerland where any comprehensive strategy against tobacco consumption is lacking, with no information campaign, no price policy, and few restrictions on advertising (a ban on cigarette advertising has recently been rejected by referendum [26]).

Men and women reported higher leisure-time physical activity over the three surveys, but this trend was partially counteracted by a decline in physical activity at work. Furthermore, the increase in the leisure-time physical activity score was more marked in the oldest age group (55-74), corresponding to an increase in "soft" physical activities (i.e., walking and gardening) rather than in aerobic and vigorous exercise. These mechanisms might explain why HDL cholesterol, which proved a reliable marker of physical activity effort at high levels [27], did not rise in response to the upward trend in more effort-demanding leisure time. Regular moderate-intensity activity should be encouraged as it has been shown to provide substantial health benefits, including a lower risk of CHD [28], and to be achieved and maintained in promotion programs [29].

The changing pattern of food consumption observed in the Vaud-Fribourg region was characterized by the lowering score of fatty diet and by the switch from butter toward margarine, from unskimmed toward skimmed milk, and from meat toward fish. These changes led very likely to the reduction in the intake of total fat or, at least, of saturated fat in the average diet. On the other hand, the frequencies of daily intakes did not change significantly across the three surveys for fruits, vegetables, and starches. As a result, there was no significant shift from an animal-based diet to a plant-based diet, presumably richer in fiber, contrary to the recommendations of American public health professionals [30]. To what extent the cardioprotective effects of such a dietary shift is caused by the decrease in saturated fat intake and by the increase in fiber intake is still controversial [31].

Average total cholesterol concentration levels increased from the first to the second survey and fell in the third survey slightly below their initial level. The same pattern of evolution was observed for the prevalence of high cholesterol. The peak in the second survey occurred uniformly in all sex-age groups and raises the possibility of a systematic measurement error in 19881989 , but the external quality control of laboratory performance did not detect any consistent bias over that time interval.

A steady decline in the average HDL concentrations was observed over time across all sex-age groups when HDL values of the first survey were corrected for a systematic bias in laboratory analysis. This decline is highly correlated with the drop in the average score of fatty diet and the correlation is physiologically plausible insofar as low-fat diets have been found to reduce generally HDL levels [32]. Furthermore, among men, the more accentuated HDL downward trend is also significantly associated with the lowering alcohol intake, which is known to influence directly HDL cholesterol [33]. The lesser reduction of HDL levels among women might be due to an increase in estrogen use, which modifies the profile of blood lipids [34]. Unfortunately, no information was available about trend in estrogen use over the study period, although the trend in use is likely to be upward as observed in other countries [35]. 
The steady decline of the HDL cholesterol levels over the study period, in parallel with inconsistent variation of total cholesterol, raises concern about potential increase in the risk of CHD.

Declining HDL levels, in parallel with relatively stable total cholesterol levels, has been reported recently in other countries [36-38]. It is unclear from these reports to which mechanism the HDL decline is related as, among humans, HDL cholesterol is lowered either by restriction of total fat intake, irrespective of the type of fat, or by substitution of saturated fat intake with polyunsaturated fat intake $[39,40]$. It was suggested that a reduction in the consumption of saturated fat, with a probable increase in total fat intake, may be involved in the long-lasting favorable trends in blood lipids (increasing HDL levels and decreasing total cholesterol levels) observed at national level in the United States [20]. However, increasing total fat intake in the average diet may lead to upward trends in BMI levels and in prevalence of obesity, as observed in many countries, including Germany and the United States (Table 6). In the Vaud-Fribourg region, the gain over time in relative weight was modest in comparison and obesity became significantly more frequent only among middle-aged men, possibly as a side effect of the decline in smoking. Weight increased in most age groups, but this was largely due to an increase of height (attributable to a birth-cohort effect due to the improvement of environment during infancy).

The time trends in blood pressure were different between sexes in the Vaud-Fribourg region. The increasing prevalence of untreated hypertension among older men requires a more rigorous control from family doctors and a higher compliance from male patients. The latter should be better informed about the dangers of hypertension. The decline in mean systolic blood pressure levels among women age less than 55 years is associated with their decreasing average score of fatty diet and with their lowering frequency of meat consumption. The second association is possibly causal since controlled trials have shown that systolic blood pressure drops approximately $6 \mathrm{~mm} \mathrm{Hg}$ among human omnivores adopting vegetarian diets [41]. According to this, the switch toward a less carnivorous diet in young and middle-aged women may have contributed to the observed $3 \mathrm{~mm} \mathrm{Hg}$ downward shift in their whole systolic blood pressure distribution.

How do the changes in CHD risk factors compare with the trends in overall CHD event rate, including deaths and hospital admissions, in the population of Vaud-Fribourg over the study period? The agestandardized CHD event rate fell by $14 \%$ among men 25 to 74 years of age, corresponding to a $25 \%$ decline in mortality rate and a $10 \%$ decline in hospitalization rate. More than half of the decline in CHD event rate is due to a decline over time in the proportion of fatal CHD events, to which the recent improvements in the hospital management of myocardial infarction have likely contributed to the greatest part. Roughly half of the fall in CHD event rate is left to the potential impact of the observed reduction of the risk factor levels, allowing for some direct effect on the declining severity of heart attacks. This estimation is compatible with the results of follow-up studies on successive cohorts in Finland [42] and the United States [43] suggesting that the changes in risk factors contributed to approximately half of the CHD mortality decline in these countries.

\section{CONCLUSION}

This study was intended to assess the time trends in lifestyle and in the major CHD risk factors over the decade 1984-1993 within six sex-age population groups of the Vaud-Fribourg region. The most favorable changes were observed in reported behaviors: increased physical activity in leisure time, healthier dietary habits associated with a decrease in fat intake, and less cigarette smoking (only among men). These changes in lifestyle were not reflected by favorable trends in objective measurements like body mass index and blood lipids. On one hand, these findings are interesting because they address the issue of questionnaire survey versus health examination survey in the monitoring of the CHD risk factors. On the other hand, they stress the need for further epidemiological work to elucidate the complex interplay between diet, lipid levels, and relative weight.

The following recommendations can be given in the state of the art: further promotion of physical activity, even at moderate intensity, and higher consumption of fruits, vegetables, and other food sources of fiber, especially among young adults. Special attention should be devoted also to middle-aged women for their increasing proportion of regular smokers and to older men for their rising prevalence of untreated hypertension. Comprehensive programs addressing several risk factors and emphasizing a greater change in perception, in the line of the Ottawa Charter [44], should be implemented, although it remains unclear how specific community intervention can be more effective than nonspecific secular modification [45-48].

\section{REFERENCES}

1. Dwyer T, Hetzel BS. A comparison of trends of coronary heart disease mortality in Australia, USA and England and Wales with reference to three major risk factors-hypertension, cigarette smoking and diet. Int J Epidemiol 1980;9(1):65-71.

2. Vartiainen E, Puska P, Pekkanen J, Tuomelehto J, Jousilahti P. Changes in risk factors explain changes in mortality from ischaemic heart disease in Finland. BMJ 1994;309:23-7.

3. Sigfusson N, Sigvaldason H, Steingrimsdottir L, Gudmundsdottir II, Stefansdottir I, Thorsteinsson T, et al. Decline in ischaemic heart disease in Iceland and change in risk factor levels. BMJ 1991;302:1371-5. 
4. Menotti A, Scanga M. Trends in coronary risk factors in Italy. Int J Epidemiol 1992;21(5):883-91.

5. Dobson AJ. Trends in cardiovascular risk factors in Australia, 1966-1983: evidence from prevalence surveys. Community Health Stud 1987;XI(1):2-14.

6. Goldman L, Cook EF. The decline in ischemic heart disease mortality rates: an analysis of the comparative effects of medical interventions and changes in lifestyle. Ann Intern Med 1984; 101:825-36.

7. Beaglehole R. International trends in coronary heart disease mortality, morbidity and risk factors. Epidemiol Rev 1990;12:115.

8. La Vecchia C, Levi F, Negri E, Randriamiharisoa A, Schüler G, Paccaud F, et al. Trends in mortality from coronary heart and cerebrovascular disease in Switzerland, 1969-87. Soz Praventivmed 1991;36:18-24.

9. WHO MONICA Project. WHO MONICA project: objectives and design. Int J Epidemiol 1989;18 Suppl 1:S29-37.

10. WHO MONICA Project. Myocardial infarction and coronary deaths in the World Health Organization MONICA project: registration procedures, event rates, and case fatality rates in 38 populations from 21 countries in four continents. Circulation 1994;90:583-612.

11. Wietlisbach V. Théorie et pratique de l'échantillonnage: l'exemple de l'enquête MONICA [Theoretical and practical aspects of sampling: the MONICA Project] [French]. Soz Praventivmed 1987;32:52-62.

12. Sequeira MM, Rickenbach M, Wietlisbach V, Tullen B, Schutz Y. Physical activity assessment using a pedometer and it comparison with a questionnaire in a large population survey. Am J Epidemiol 1995;142:989-99.

13. Cloey T, Bachorik PS, Becker D, Finney C, Lowry D, Sigmund $\mathrm{W}$, et al. Reevaluation of serum-plasma differences in total cholesterol concentration. JAMA 1990;263:2788-9.

14. Burnand B, Hausser D, Rickenbach M, Platsoukas C, Gutzwiller F. Cholestérol plasmatique total et HDL dans la population en Suisse: quelle attitude et quelles normes adopter? [Cholesterol values in a Swiss population: which norms to adopt?] [French]. Soz Praventivmed 1988;33:60-67.

15. Groupe de Travail Lipides de la Fondation Suisse de Cardiologie et de la Société Suisse de Cardiologie. Lipides et prévention des maladies coronariennes: diagnostic et mesures thérapeutiques [Blood lipids and prevention of coronary heart diseases: diagnosis and treatment] [French]. Schweiz Med Wochenschr 1992;73: $1-10$.

16. SPSS, Inc. SPSS reference guide. Release 4.0. Chicago: SPSS, Inc., 1990.

17. WHO MONICA Project. WHO MONICA project: risk factors. Int J Epidemiol 1989;18(3 Suppl 1):S46-S55.

18. Hoffmeister H, Mensink GBM, Stolzenberg H. National trend in risk factors for cardiovascular disease in Germany. Prev Med 1994;23:197-205.

19. Vartiainen E, Puska P, Jousilahti P, Korhonen HJ, Tuomilehto $\mathrm{J}$, Nissinen A. Twenty-year trends in coronary risk factors in North Karelia and other areas in Finland. Int $\mathrm{J}$ Epidemiol 1994;23(3):495-504.

20. Johnson CL, Rifkink BM, Sempos CT, Carroll MD, Bachorik PS, Briefel RR, et al. Declining serum total cholesterol levels among US adults: the National Health and Nutrition Examination Surveys, 1960 to 1991. JAMA 1993;269(23):3002-8.

21. Kuczmarski RJ, Flegal KM, Campbell SM, Johnson CL. Increasing prevalence of overweight among US adults: the National Health and Nutrition Examination Surveys, 1960 to 1991. JAMA 1994;272(3):205-11.

22. Wietlisbach V, Barazzoni F. Echantillonage et analyse de la par- ticipation pour la deuxième enquête de population (1988-1989) sur les facteurs de risque cardiovasculaires [Outcome and analysis of participation in the second MONICA survey (1988-1989) of cardiovascular risk factors] [French]. Schweiz Med Wochenschr 1993;123 Suppl 48:13-20.

23. Hopkins PN, Williams RR. A survey of 246 suggested coronary risk factors. Atherosclerosis 1981;40:1-52.

24. Willet W. Nutritional epidemiology. New York: Oxford Univ. Press, 1990.

25. La Vecchia C. Smoking in Italy, 1949-1983. Prev Med 1986;15: 274-81.

26. Cornuz J, Burnand B, Kawachi I, Gutzwiller F, Paccaud F. Why did Swiss citizens refuse to ban tobacco advertising? Tobacco Control. 1996;5:149-53.

27. Williams PT. High-density lipoprotein cholesterol and other risk factors for coronary heart disease in female runners. $\mathrm{N}$ Engl $\mathrm{J}$ Med 1996;334:1298-303.

28. Pate RR, Pratt M, Blair SN, Haskell WL, Macera CA, Bouchard $\mathrm{C}$, et al. Physical activity and public health; a recommendation from the Centers for Disease Control and Prevention and the American College of Sports Medicine. JAMA 1995;273(5): 402-7.

29. Hillsdon M, Thorogood M, Anstiss T, Morris J. Randomised controlled trials of physical activity promotion in free living populations: a review. J Epidemiol Community Health 1995;49:44853.

30. Marshall JR. Improving Americans' diet: setting public policy with limited knowledge [editorial]. Am J Public Health 1995;85(12):1609-10.

31. Wynder EL, Stellman SD, Zang EA. High fiber intake, indicator of healthy lifestyle. [Editorial]. JAMA 1996;275(6):486-7.

32. Grundy SM, Denke MA. Dietary influences on serum lipids and lipoproteins. J Lipid Res 1990;31:1149-72.

33. Gaziano JM, Buring JE, Breslow JL, Goldhaber SZ, Rosner B, Vandenburgh M, et al. Moderate alcohol intake, increased levels of high-density lipoprotein and its subfractions, and decreased risk of myocardial infarction. N Engl J Med 1993;329:1829-34.

34. Matthews KA, Meilahn E, Kuller LH, Kelsey SF, Caggiula AW, Wing RR. Menopause and risk factors for coronary heart disease. N Engl J Med 1989;321:641-6.

35. Derby CA, Hume AL, Barbour MM, MacPhillips JB, Lasater TM, Carleton RA, et al. Correlates of postmenopausal estrogen use and trends through the 1980s in two southeastern New England communities. Am J Epidemiol 1993;137:1125-35.

36. Fortmann SP, Taylor CB, Flora JA, Winkleby MA. Effect of community health education on plasma cholesterol levels and diet: the Stanford Five-City Project. Am J Epidemiol 1993;137(10): 1039-55.

37. Bennett SA, Magnus P. Trends in cardiovascular risk factors in Australia: results from the National Heart Foundation's Risk Factor Prevalence Study, 1980-1989. Med J Aust 1994;161:519_ 27.

38. Jackson R, Yee RL, Priest P, Shaw L, Beaglehole R. Trends in coronary heart disease risk factors in Auckland 1982-94. N Z Med J 1995;108:451-4.

39. Mattson FH, Grundy SM. Comparison of effects of dietary saturated, monounsaturated, and polyunsaturated fatty acids on plasma lipids, and lipoproteins in man. J Lipid Res 1985;26:194202.

40. Pietinen $\mathrm{P}$, Huttunen JK. Dietary determinants of plasma highdensity lipoprotein cholesterol. Am Heart J 1987;113(2):620-5.

41. Barnard ND, Nicholson A, Howard JL. The medical costs attributable to meat consumption. Prev Med 1995;24:646-55.

42. Jousilahti P, Vartiainen E, Tuomilehto J, Pekkanen J, Puska P. 
Effect of risk factors and changes in risk factors on coronary mortality in three cohorts of middle-aged people in Eastern Finland. Am J Epidemiol 1991;41(1):50-60.

43. Sytkowski PA, Kannel WB, d'Agostino RB. Changes in risk factors and the decline in mortality from cardiovascular disease: the Framingham Heart Study. N Engl J Med 1990;322(32): 1635-41.

44. Ottawa charter for health promotion. Health Promot 1987;1:III-V.

45. Salonen JT. Prevention of coronary heart disease in Finlandapplication of the population strategy. Ann Med 1991;23:60712.
46. Farquan JW, Fortmann SP, Flora J, Taylor CB, Haskell WL, Williams PT, et al. Effects of community-wide education on cardiovascular disease risk factors: the Stanford Five-City Project. JAMA 1990;264:359-65.

47. Luepker RV, Murray DM, Jacobs DR, Mittelmark MB, Bracht N, Carlaw R, et al. Community education for cardiovascular disease prevention: risk factor changes in the Minnesota Heart Health Program. Am J Public Health 1994;84(9):1383-93.

48. Winkleby MA. The future of community-based cardiovascular disease intervention studies. Am J Public Health 1994;84(9): 1369-72. 